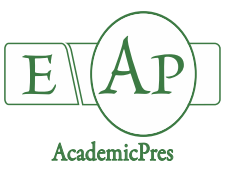

Mosavian SN et al. (2021)

Notulae Botanicae Horti Agrobotanici Cluj-Napoca

Volume 49, Issue 2, Article number 12252

DOI: $10.15835 /$ nbha 49212252

Research Article

\title{
Do nitrogen and zinc application alleviate the adverse effect of heat stress on wheat ( Triticum aestivum L.)?
}

\section{Seyed Nader MOSAVIAN ${ }^{1}$, Hamid Reza EISVAND ${ }^{1 *}$, Naser AKBARI ${ }^{1}$, Ali MOSHATATI², Ahmad ISMAILI ${ }^{1}$}

\author{
${ }^{1}$ Lorestan University, Department of Plant Production and Genetic Engineering, Iran; nader_mosavian@yahoo.com; \\ eisvand.hr@lu.ac.ir(*corresponding author);nr1332@hotmail.com;ismailia@lu.ac.ir \\ ${ }^{2}$ Agricultural Sciences and Natural Resources University of Khuzestan, Department of Plant Production and Genetics, Iran; \\ A.moshatati@asnrukh.ac.ir
}

\begin{abstract}
Late-season heat stress (LSH) is a limiting factor for wheat production. Besides, low zinc and poor protein diet usually is a problem in low-income countries. The primary calorie source in such countries is prepared from bread. This study aims to mitigate heat stress by zinc and nitrogen application and improve zinc and protein content in wheat grain. We did the field experiments as a split-split-plot based on a randomized complete block design with four replications to assess zinc and nitrogen's possible mitigation effect on LSH and protein and zinc enrichment of wheat grain during two years. Factors included LSH by delay in planting date (optimum, late, and very late) as the main plot, nitrogen $\left(0,75,150\right.$, and $\left.225 \mathrm{~kg} \mathrm{ha}^{-1}\right)$ in subplots, and zinc $\left(0,10\right.$, and $\left.20 \mathrm{~kg} \mathrm{ha}^{-1}\right)$ as sub-subplots. We measured yield, yield components, physiological traits, zinc, and protein contents in the grain. Results showed that the highest relative water content and cell-membrane thermal stability were attained at the optimum planting date, $150 \mathrm{~kg} \mathrm{~N} \mathrm{ha}^{-1}$ and $20 \mathrm{~kg} \mathrm{Zn} \mathrm{ha}^{-1}$. The maximum chlorophyll a and carotenoids contents in wheat cells were recorded in the optimum planting date, $225 \mathrm{~kg} \mathrm{~N}$ $\mathrm{ha}^{-1}$, and $20 \mathrm{~kg} \mathrm{Zn} \mathrm{ha}^{-1}$. Heat stress reduced the grain yield. In the second year of the experiment, the grain number per unit area was more than that of the first year; however, the highest grain yield was achieved in the first year owing to the higher mean grain weight. Nitrogen application decreased the adverse effects of heat stress on grain yield by increasing the grain number. Zinc application diminished the adverse effects of heat stress by increasing the mean grain weight. The adverse impact of the LSH on grain yield was more than that of biological yield. Heat stress reduced the hectolitre weight and zinc content of the grain. Meanwhile, it increased grain protein. In general, under LSH, the application of $225 \mathrm{~kg} \mathrm{~N} \mathrm{ha}^{-1}$ and $20 \mathrm{~kg} \mathrm{Zn} \mathrm{ha}^{-1}$ can reduce the adverse effects of heat on the grain quality and quantity.

Keywords: biofortification; cell-membrane thermal stability; fertilizers; planting date

Abbreviations: Car., Carotenoids; Chl a, chlorophyll a; Chl b, Chlorophyll b; CMTS, Cell membrane thermal stability; DW, Dry weight; FW, Fresh weight; GN, Grain number per unit area; GP, grain protein content; GW, 1000-grain weight; GY, grain yield; GZ, grain zinc content; HL, grain hectolitre; HSP, Heat shock protein; LPD, Late planting date; LSH, Late-season heat stress; N, Nitrogen; OPD, Optimum planting date; RCBD, Randomized complete block design; RWC Relative water content; TW, Turgid weight; VLPD, Very late planting date; Zn, Zinc

Received: 05 Feb 2021. Received in revised form: 03 Mar 2021. Accepted: 09 Mar 2021. Published online: 29 Apr 2021.

From Volume 49, Issue 1, 2021, Notulae Botanicae Horti Agrobotanici Cluj-Napoca journal uses article numbers in place of the traditional method of continuous pagination through the volume. The journal will continue to appear quarterly, as before, with four annual numbers.
\end{abstract}




\section{Introduction}

As the primary source of humans' daily calorie intake, wheat plays a significant role in food security worldwide. This crop is also a critical source of protein, mineral nutrients, and vitamins, particularly B-group vitamins (Halim et al., 2018). Considering a close relationship among soils, crops, and human health nutrition, plant growth in zinc-deficient soils results in low zinc seeds, causing zinc deficiency in humans and animals fed such seeds, which will result in many health-related side effects (Niyigaba et al., 2019).

In the southwest of Iran, wheat is cultivated during late autumn. Under such conditions, the vegetative wheat growth coincides with cool-season precipitations, and no environmental limitations related to weather affect the vegetative growth. However, in the late-season of wheat growth, there exist limitations related to increased air temperature and water deficit, negatively impacting crop growth and production. Moshatati and Mousavi (2017) observed that late-season heat stress reduced wheat grain yields up to $48 \%$. They reported that the highest and lowest grain yield belonged to the early November and early January planting dates. Delay in planting can cause a $65 \%$ reduction in grain yield because of late-season heat stress (Asakereh-Nezhad and Lak, 2017). It is concluded that heat stress reduces the biological yield by imposing premature aging on photosynthetic organs and lowering the current assimilates (Pireivatlou et al., 2010). Cell membrane damage, electrical leakage from thylakoid, and reduced chlorophyll content are the adverse effects of heat stress, ultimately decreasing the photosynthesis performance (Rehman et al., 2016). It is essential to use nitrogen and zinc efficiently to mitigate the undesirable influences of heat on crop yield and growth (Hafez and Badawy, 2018).

Nutrient deficiency is an important environmental limitation experienced by wheat during its growth and development. Zinc deficiency in the soil reduces wheat yield and grain Zn content (Niazkhani et al., 2018). Almost $60 \%$ of the cultivated soils globally, especially soils in arid and semi-arid regions, are zinc deficient, leading to a more than $50 \%$ reduction in crop yield (Yang et al., 2014). Zinc deficiency leads to the inefficiency of metabolic and enzymatic defence systems associated with stress resistance. Zinc improves the growth of the root and stem of cereals, hence produce vigour plants that will be more tolerant against stress and have more grain yield (Bechoff and Dhuique-Mayer, 2016). Besides, zinc deficiency in soils and plants is a global micronutrient deficiency problem reported in many countries, and it is registered as a risk factor for human health universally. Confirming acceptable levels of zinc in diets and its intake should be a key constituent in reducing child illness, improving physical growth, and decreasing death in developing countries (Chiranjib and Kumar, 2010). Zinc increases the grain protein content by activating protein synthesis enzymes (Saleem et al., 2015).

High temperatures reduce photosynthesis because of damage to chlorophyll pigments, a decline in leaf nitrogen, obstruction of PSII reaction centre and electron flow, decreased quantum efficiency, and downregulation of PSII photochemistry (Fahad et al., 2017). In addition to the role of nitrogen in plant growth, it has been shown that high nitrogen regimes induce more heat shock proteins (mitochondrial Hsp60 and chloroplastic Hsp24) that confer heat tolerance to plant (Heckathorn et al., 1996). In irrigated wheat fields, where no nitrogen deficiencies occur, the most influential factor on the grain protein content is the air temperature during the grain-filling period. It has been reported that high temperature enhanced the wheat protein content (Velu et al., 2016).

As the essential food source, wheat experiences high temperatures and low precipitation during the grain

filling period in Iran. Also, large areas of wheat cultivated lands have low available zinc for plants. Hence, the current research was designed to assess the probable heat stress mitigation effect of zinc and nitrogen fertilizers on wheat yield and zinc bio-fortification for improving wheat grain quality (protein and zinc content) under control and the heat stress conditions. 


\section{Materials and Methods}

This research was carried out during two successive growing seasons of 2018 and 2019 in the research field $\left(31^{\circ} 36^{\prime} \mathrm{N}, 48^{\circ} 53^{\prime} \mathrm{E}\right.$, and $34 \mathrm{~m}$ above sea level) of Khuzestan University of Agriculture and Natural Resources, Molassani, Iran. The experimental site was placed in a semi-arid area with an average annual temperature and precipitation of $26.6^{\circ} \mathrm{C}$ and $213 \mathrm{~mm}$, respectively. Some chemical and physical features of the soil, meteorological data of the experimental site, as well as the trend of Tmax during the experiments in relation to wheat growth stages during the study period are given in Tables 1 and 2, and Figure 1 respectively.

Table 1. Soil physicochemical properties of the experimental farm

\begin{tabular}{|c|c|c|c|c|c|c|c|c|c|}
\hline Year & Texture & $\mathrm{pH}$ & $\begin{array}{c}\mathrm{EC} \\
\left(\mathrm{dS} \mathrm{cm}^{-1}\right)\end{array}$ & $\begin{array}{c}\text { Organic } \\
\text { matter }(\%)\end{array}$ & $\begin{array}{c}\mathrm{N} \\
(\%)\end{array}$ & $\begin{array}{c}\mathrm{P}_{2} \mathrm{O}_{5} \\
(\%)\end{array}$ & $\begin{array}{c}\mathrm{Zn} \\
\left(\mathrm{mg} \mathrm{kg}^{-1}\right)\end{array}$ & $\begin{array}{c}\mathrm{Fe} \\
(\%)\end{array}$ & $\begin{array}{c}\mathrm{K} \\
(\%)\end{array}$ \\
\hline $\begin{array}{c}\text { The First } \\
\text { year }\end{array}$ & Silty clay loam & 6.99 & 2.59 & 1.33 & 0.0336 & 0.05 & 0.014 & 0.016 & 0.378 \\
\hline $\begin{array}{c}\text { The second } \\
\text { year }\end{array}$ & Silty clay loam & 6.80 & 2.80 & 0.53 & 0.0328 & 0.04 & 0.012 & 0.013 & 0.365 \\
\hline
\end{tabular}

Table 2. Some meteorological data of the experimental site during 2017-2018 and 2018-2019 growing seasons

\begin{tabular}{|c|c|c|c|c|c|c|c|c|c|c|c|c|}
\hline \multirow{3}{*}{ Months } & \multicolumn{4}{|c|}{ Temperature $\left({ }^{\circ} \mathrm{C}\right)$} & \multicolumn{4}{|c|}{ Relative humidity (\%) } & \multicolumn{2}{|c|}{ Sunshine sum } & \multicolumn{2}{|c|}{ Rainfall (mm) } \\
\hline & \multicolumn{2}{|c|}{ Min } & \multicolumn{2}{|c|}{ Max } & \multicolumn{2}{|c|}{ Min } & \multicolumn{2}{|c|}{ Max } & Mean & Mean & Mean & Mean \\
\hline & 2018 & 2019 & 2018 & 2019 & 2018 & 2019 & 2018 & 2019 & 2018 & 2019 & 2018 & 2019 \\
\hline December & 9.3 & 12.5 & 22.5 & 21.8 & 15.9 & 17.1 & 56.7 & 77.5 & 206.9 & 157.8 & 18.7 & 103.6 \\
\hline January & 8.8 & 9.7 & 23.2 & 18.2 & 16.0 & 14.0 & 53.1 & 74.5 & 218 & 126 & 1.5 & 27.1 \\
\hline February & 8.8 & 9.7 & 23.3 & 20.6 & 16.6 & 15.2 & 53.5 & 67.3 & 190.5 & 198.8 & 8.0 & 33.3 \\
\hline March & 14.2 & 10.7 & 27.4 & 23.5 & 20.8 & 17.1 & 50.4 & 54.4 & 275.2 & 239.8 & 36.6 & 11.8 \\
\hline April & 18.1 & 16.6 & 33.1 & 29.7 & 25.6 & 23.1 & 43.3 & 52 & 199.6 & 220.7 & 32.7 & 45.4 \\
\hline May & 22.6 & 21.3 & 36.3 & 36.7 & 29.5 & 29.0 & 30.4 & 34 & 263.3 & 334.5 & 12.2 & 2.2 \\
\hline
\end{tabular}

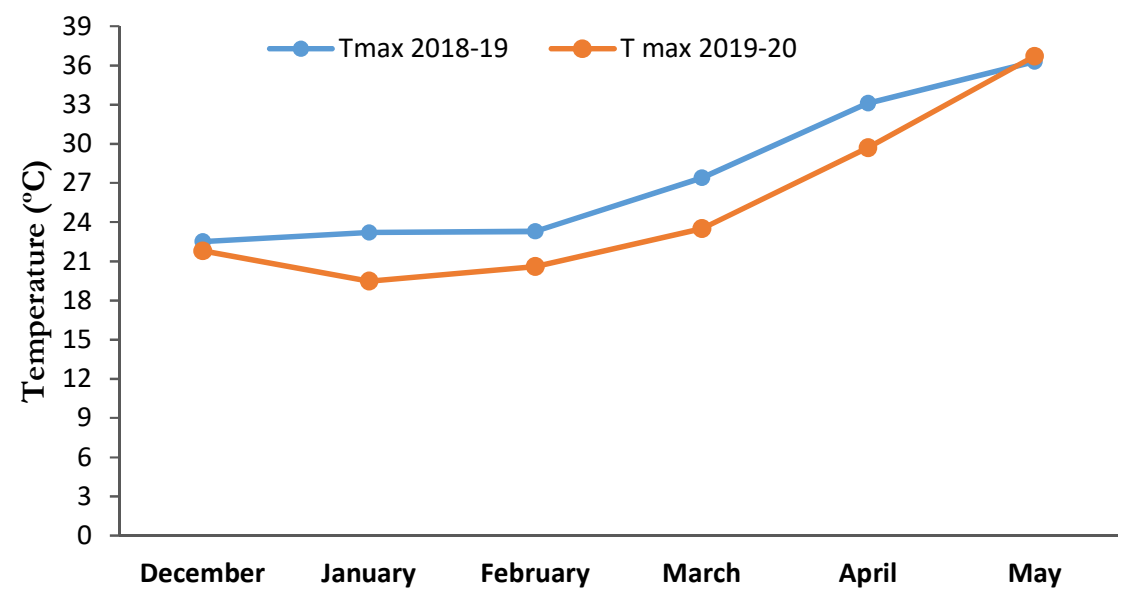

Figure 1. The trend of Tmax during the experiments in relation to wheat growth stages

\section{Experimental design}

The research was conducted using a split-split plot based on a randomized complete block design with four replications. Experimental factors were three planting dates, including November 22 (as an appropriate planting date), December 11 (late planting date), and December 31 (very late planting date) as main plots, four nitrogen levels, including $0,75,150$, and $225 \mathrm{~kg} \mathrm{ha}^{-1}$ as subplots, and three zinc levels, namely $0,10.0$, and 20.0 
$\mathrm{kg} \mathrm{ha}^{-1}$ as sub-sub plots. Urea (containing $46 \% \mathrm{~N}$ ) and zinc sulfate (containing $14.7 \%$ zinc) were used as fertilizer sources. The field experiment had 144 plots. Each plot area was $4 \mathrm{~m}^{2}(2 \mathrm{~m} \times 2 \mathrm{~m}$ with 10 planting rows of $2 \mathrm{~m}$ lengths), with $60 \mathrm{~cm}, 90 \mathrm{~cm}$, and $300 \mathrm{~cm}$ wide ridge between two neighbouring sub-sub plots, subplots, and main plots, respectively. The entire experimental plots were 144 each year.

\section{Crop management}

Wheat (Chamran 2 cultivar) was cultivated on three planting dates. The planting density was 400 plants $\mathrm{m}^{-2}$. Chamran 2 is a cultivar resistant to rust and lodging. Field preparation (plowing and land levelling), weed and pest control, and irrigation were carried out according to typical region practices. All plots were given identical applications of $\mathrm{P}$ at $100 \mathrm{~kg} \mathrm{ha}^{-1}$ as superphosphate triple and $\mathrm{K}$ at $100 \mathrm{~kg} \mathrm{ha}^{-1}$ as potassium sulfate, as recommended by soil analysis. Nitrogen treatments were applied three times: one-third before planting at land preparation time, one-third at tillering stage, and one-third at the onset of the stem extension period. Zinc treatment was applied at the mid-stage of tillering. Zinc sulfate was dissolved in water, and the obtained solution was added to the soil close to the plant crown.

\section{Measuring indices and methods}

Growth stage recording

For all treatments, time to reach a specific growth stage was recorded (Table 3).

Table 3. The time of occurring growing stages of wheat at different planting dates

\begin{tabular}{|c|c|c|c|c|c|c|}
\hline \multirow{2}{*}{$\begin{array}{l}\text { Growth } \\
\text { stage }\end{array}$} & \multicolumn{2}{|c|}{ First planting date (22Nov) } & \multicolumn{2}{|c|}{ Second planting date $(11 \mathrm{Dec})$} & \multicolumn{2}{|c|}{ Third planting date (31 Dec) } \\
\hline & 2018 & 2019 & 2018 & 2019 & 2018 & 2019 \\
\hline $\begin{array}{l}\text { Seedling } \\
\text { emergence }\end{array}$ & $\operatorname{Nov} 28\left(7^{*}\right)$ & $\operatorname{Dec} 31(10)$ & Dec $18(7)$ & $\operatorname{Dec} 23(11)$ & Jan $8(8)$ & Jan $12(11)$ \\
\hline Tillering & $\operatorname{Jan} 6(46)$ & Jan $16(56)$ & Jan $27(47)$ & Feb $6(55)$ & Feb $26(27)$ & Mar $8(35)$ \\
\hline Stem elongation & Feb $10(81)$ & Feb 20 (91) & Feb $26(77)$ & Mar $8(85)$ & Mar $14(73)$ & Mar $24(81)$ \\
\hline Flowering & Feb $23(94)$ & $\operatorname{Mar} 7(106)$ & Mar $15(94)$ & Mar $27(105)$ & Mar 25 (85) & Apr $10(98)$ \\
\hline $\begin{array}{l}\text { Grain } \\
\text { maturation }\end{array}$ & Apr 13 (143) & Apr 10 (156) & Apr 24 (134) & May 7 (146) & Apr 27 (117) & May $17(135)$ \\
\hline
\end{tabular}

${ }^{*}$ indicates the number of days after planting

Yield

At maturity (when the moisture content of grains reached 14\%), all plants in each plot were harvested; above-ground biomass, the number of seed per unit area, weight of 1000-grain, and final grain yields were further determined. Each plot's harvest index was measured by dividing the grain yield by the above-ground biomass (Dai et al., 2016).

\section{Physiological traits}

At the flowering stage, cell membrane thermal stability (CMTS), carotenoid content, chlorophyll a, chlorophyll $\mathrm{b}$, relative water content, and wheat canopy temperature were measured as the physiological responses of wheat to the experimental treatments. CMTS was determined based on a method presented by Agarie et al. (1995). For each plot, the flag leaves of 10 plants were selected to measure carotenoids content, chlorophyll a, and chlorophyll b with a spectrophotometer (SPEKOL2000) using the Arnon method (1967). Relative water content was measured using a $5 \mathrm{~cm}^{2}$ surface of the flag. The samples' fresh weight was measured; the samples were floated on distilled water for seven hours in darkness. The turgid weight of samples was determined. Afterward, to specify the dry weight of samples, they were dried at $75^{\circ} \mathrm{C}$ for $48 \mathrm{~h}$. Relative water was measured using the following equation:

$\mathrm{RWC}=[(\mathrm{FW}-\mathrm{DW}) /(\mathrm{TW}-\mathrm{DW})] \times 100$

Where DW is dry weight, FW is fresh weight, TW and is the turgid weight. 


\section{Grain quality}

Protein (\%) and zinc $\left(\mathrm{mg} \mathrm{kg}^{-1}\right)$ contents were determined as grain quality indices. Protein content was measured by the NIR grain analyzer (7250, Perten Company, Sweden). Atomic absorption (240FS AA, Agilent Company, USA) was used to measure grains' zinc content. Hectolitre was determined, according to Hill's (1975) method.

\section{Data analysis}

A combined analysis of the data about yield and yield components, physiological traits, and grain quality was carried out using SAS ver.9.4 (SAS Institute Inc., Cary, NC, USA). Because of page limitations, ANOVA tables are not included in the manuscript. However, means comparison is shown. The mean comparisons of various treatments were carried out utilizing Duncan’s Multiple Range Test.

\section{Results}

\section{Relative water content ( $R W C$ ) of wheat}

The compound analysis showed that year and interaction of planting date $\times$ nitrogen $\times$ zinc on RWC were significant $(\mathrm{P} \leq 0.01$, Table 10). Delay in planting caused a significant reduction in leaf RWC, were late and very late planting dates, respectively, had $3.28 \%$ and $5.55 \%$ lower RWC than the optimal planting date (Table 4). The highest RWC (83.40\%) was obtained at optimal planting date using $150 \mathrm{~kg} \mathrm{ha}^{-1} \mathrm{~N}$ and $20 \mathrm{~kg}$ ha ${ }^{-1} \mathrm{Zn}$. The lowest RWC (61.64\%) belonged to the very late planting date with no usage of $\mathrm{N}$ and zinc fertilizers (control), which was $26 \%$ lower than that of the highest value (Table 4). RWC of the second year of the experiment was higher than that of the first year (Table 5). When wheat was sowed late (late planting date), the highest RWC was attained using $225 \mathrm{~kg} \mathrm{ha}^{-1} \mathrm{~N}$ and $10 \mathrm{~kg} \mathrm{ha}^{-1}$ Zinc. Under the conditions of very late planting, the highest RWC was achieved with the application of $150 \mathrm{~kg} \mathrm{ha}^{-1} \mathrm{~N}$ and $20 \mathrm{~kg} \mathrm{ha}^{-1}$ zinc (Table 4).

\section{Cell membrane thermal stability (CMTS)}

According to the results, year and interaction of planting date $\times$ nitrogen $\times$ zinc significantly affected CMTS $(\mathrm{P} \leq 0.01$, Table 10). Delay in planting reduced CMTS, where late and very late planting dates caused $6.45 \%$ and $13.1 \%$ reductions in CMTS, respectively. The mean comparison of the data showed that the highest CMTS $\left(52.25 \mu\right.$ mhos. $^{-1}$ ) belonged to the treatment with optimal planting date, $150 \mathrm{~kg} \mathrm{ha}^{-1} \mathrm{~N}$ and $20 \mathrm{~kg}$ $\mathrm{ha}^{-1}$ zinc. However, the lowest CMTS $\left(21.63 \mu\right.$ mhos. $\left.\mathrm{cm}^{-1}\right)$ was observed in a very late planting date with no N and Zinc application (control treatment). There was a $65.79 \%$ reduction in CMTS in the second year compared to the first year of the experiment (Table 5). Regarding the interaction of planting datex fertilizer, $225 \mathrm{~kg} \mathrm{ha}^{-1} \mathrm{~N} ; 20 \mathrm{~kg} \mathrm{ha}^{-1}$ Zinc, $75 \mathrm{~kg} \mathrm{ha}^{-1} \mathrm{~N} ; 10 \mathrm{~kg} \mathrm{ha}^{-1}$ Zinc and $225 \mathrm{~kg} \mathrm{ha}^{-1} \mathrm{~N}$ and $20 \mathrm{~kg} \mathrm{ha}^{-1} \mathrm{Zinc}$ were required to achieve the highest CMTS under the conditions of optimal, late, and a very late planting dates, respectively (Table 4).

\section{Carotenoids, chlorophyll a, and chlorophyll $b$}

The effect of year and interaction of planting date $\times$ nitrogen $\times$ zinc on carotenoids, chlorophyll a, and chlorophyll $\mathrm{b}$ was significant $(\mathrm{P} \leq 0.01$, Table 10$)$. Late planting date had a negligible effect on chlorophyll a content, where the difference between optimal and late planting date was only $5 \%$ regarding chlorophyll a content. However, a very late planting date (with a difference of $26.27 \%$ ) significantly reduced chlorophyll a (Table 4). The same trend was observed in chlorophyll b content, where the difference of optimal planting date with late and very late planting dates was $6.5 \%$ and $32 \%$, respectively. Delay in planting resulted in increased carotenoid content, with the flag leaf of wheat having $0.83 \%$ and $5.8 \%$ higher carotenoids at optimal planting date than the late and very late planting dates, respectively (Table 4). The mean comparison of the interaction of planting date $\times$ nitrogen $\times$ zinc showed that the highest content of chlorophyll a $\left(27.22 \mathrm{mg} \mathrm{g}^{-1}\right)$ was obtained 
in optimal planting date treatment with $225 \mathrm{~kg} \mathrm{ha}^{-1} \mathrm{~N}$ and $20 \mathrm{~kg} \mathrm{ha}^{-1}$ Zinc. No fertilizer application led to the lowest $\left(12.73 \mathrm{mg} \mathrm{g}^{-1}\right)$ chlorophyll content of wheat leaf at a very late planting date (Table 4). The highest carotenoid content of flag leaf $\left(27.29 \mathrm{mg} \mathrm{g}^{-1}\right)$ was observed at the first planting date with the application of 225 $\mathrm{kg} \mathrm{ha}^{-1} \mathrm{~N}$ and $20 \mathrm{~kg} \mathrm{ha}^{-1}$ zinc. With no fertilizers applied and a very late wheat planting, the leaf had the lowest $\left(8.70 \mathrm{mg} \mathrm{g}^{-1}\right)$ carotenoids.

Regarding the effect of year, there was a considerable difference $(\mathrm{P} \leq 0.01)$ between the two years of experiment in terms of chlorophyll a and carotenoids content; specifically, the chlorophyll and carotenoids contents of flag leaf were higher in the first year (3\% and twice more than that of the second year, respectively) (Table 5). When wheat was planted with delay, $225 \mathrm{~kg} \mathrm{ha}^{-1} \mathrm{~N}$ and $10 \mathrm{~kg} \mathrm{ha}^{-1} \mathrm{Zinc}$ had to be applied for high chlorophyll content. Furthermore, to maximize wheat resistance to high-temperature stress through maximizing carotenoid content, $225 \mathrm{~kg} \mathrm{ha}^{-1} \mathrm{~N}$ and $20 \mathrm{~kg} \mathrm{ha}^{-1}$ Zinc had to be utilized under late planting conditions (Table 4). However, this amount was reduced to $150 \mathrm{~kg} \mathrm{ha}^{-1} \mathrm{~N}$ and $10 \mathrm{~kg} \mathrm{ha}^{-1}$ Zinc at the very late planting date (Table 4). The interaction of year $\times$ planting date significantly influenced the chlorophyll $b$ content $(\mathrm{P} \leq 0.01)$. The highest content of chlorophyll $\mathrm{b}$ in the two years of the experiment belonged to the LPD. However, the very late planting date had the lowest chlorophyll b content (Figure 2).

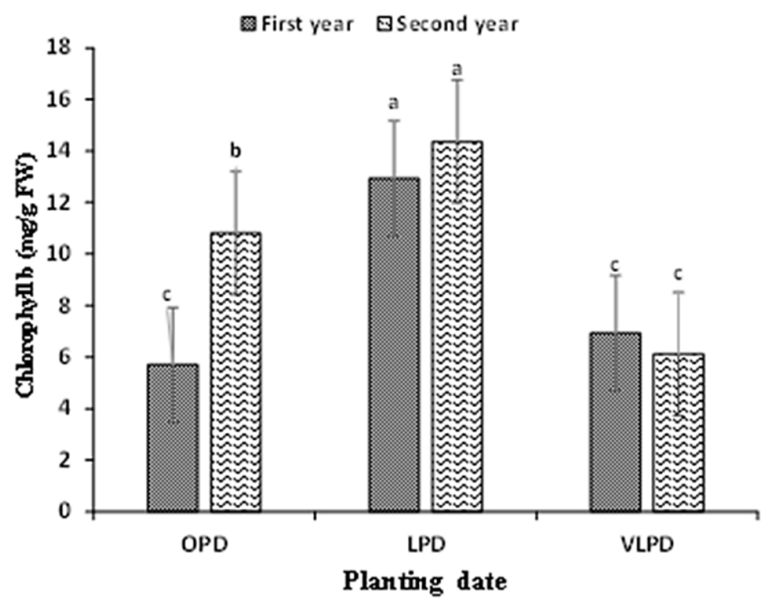

Figure 2. Chlorophyll b content of wheat leaf in different planting dates of two years of experiment OPD, LPD, and VLPD indicate optimum, late, and very late planting dates, respectively. Different letters represent a significant difference $(\mathrm{P} \leq 0.01)$ based on Duncan's multiple range test. Standard errors are also showed in the figure

\section{Grain yield}

The compound analysis revealed that the year's effect and interaction of planting date $\times$ nitrogen $\times$ zinc on the wheat grain yield were significant $(P \leq 0.01$, Table 10). In the second year, the wheat grain yield was significantly $(\mathrm{P} \leq 0.01)$ greater than that of the first year (Table 5). The mean comparison showed that the grain's highest yield was acquired when wheat was planted at optimal planting date using $225 \mathrm{~kg} \mathrm{~N} \mathrm{ha}^{-1}$ and 20 $\mathrm{kg} \mathrm{Zn} \mathrm{ha}{ }^{-1}$. A very late planting date with no fertilizer application resulted in the lowest grain yield. Delay in planting was associated with reduced grain yield. At late and very late planting dates, the achieved grain yield was $14 \%$ and $35 \%$ lower than that of the optimal planting date, respectively. However, under late and very late planting conditions, usage of $225 \mathrm{~kg} \mathrm{~N} \mathrm{ha}^{-1}$ and $150 \mathrm{~kg} \mathrm{ha}^{-1}$ and $20 \mathrm{~kg} \mathrm{Zn} \mathrm{ha}^{-1}$ resulted in the highest grain yield (Table 6).

Grain yield components were reduced by delayed planting; specifically, grain weight and number per unit area experienced $7.86 \%$ and $13.37 \%$ reduction at the late planting and $12.7 \%$ and $25.58 \%$ reduction at the very late planting dates, respectively (Table 6$)$. The highest grain weight $(47.13 \mathrm{~g})$ belonged to the optimal planting date applying $150 \mathrm{~kg} \mathrm{~N} \mathrm{ha}^{-1}$ and $20 \mathrm{~kg} \mathrm{Zn} \mathrm{ha}^{-1}$. The smallest grains were observed $(31.29 \mathrm{~g})$ in the very late planting date with no fertilizers applied, showing a reduction of $33 \%$ (Table 6). Using $225 \mathrm{~kg} \mathrm{~N} \mathrm{ha}^{-1}$ and 
$20 \mathrm{~kg} \mathrm{Zn} \mathrm{ha}^{-1}$ at the optimal planting date resulted in the highest grain number per unit area; in other words, a very late planting date without the use of nitrogen and zinc fertilizers yielded the lowest value of this trait (Table 6). To maximize the grain weight at late and very late planting dates, $150 \mathrm{~kg} \mathrm{~N} \mathrm{ha}^{-1}$ and $10 \mathrm{~kg} \mathrm{Zn} \mathrm{ha}^{-1}$ was needed. Furthermore, to maximize the grain number per unit area at late and very late planting dates, $150 \mathrm{~kg}$ $\mathrm{N} \mathrm{ha}^{-1}, 10 \mathrm{~kg} \mathrm{Zn} \mathrm{ha}^{-1}$, and $225 \mathrm{~kg} \mathrm{Nha}^{-1}, 10 \mathrm{~kg} \mathrm{Zn} \mathrm{ha}^{-1}$ had to be applied, respectively (Table 6).

Table 4. Means comparison for interaction between planting date and N-Zn fertilizers on some physiological properties of wheat

\begin{tabular}{|c|c|c|c|c|c|c|c|c|c|c|c|c|}
\hline $\begin{array}{c}\text { Planting } \\
\text { date }\end{array}$ & $\begin{array}{l}\text { Nitrogen } \\
\text { (kg ha-1) }\end{array}$ & $\begin{array}{c}\text { Zinc } \\
(\mathrm{kg} \text { ha- } 1)\end{array}$ & \multicolumn{2}{|c|}{$\begin{array}{l}\text { RWC } \\
(\%)\end{array}$} & \multicolumn{2}{|c|}{$\begin{array}{c}\text { CMTS } \\
(\mu \text { mhos.cm- } 1)\end{array}$} & \multicolumn{2}{|c|}{$\begin{array}{l}\text { Chlorophyll a } \\
\text { (mg g-1FW) }\end{array}$} & \multicolumn{2}{|c|}{$\begin{array}{l}\text { Chlorophyll b } \\
\text { (mg g-1FW) }\end{array}$} & \multicolumn{2}{|c|}{$\begin{array}{l}\text { Carotenoids } \\
\text { (mg g-1FW) }\end{array}$} \\
\hline OPD & 0 & 0 & 79.10 & $a-c$ & 43.08 & $a-c$ & 19.81 & $\mathrm{~b}-\mathrm{k}$ & 5.02 & $\mathrm{pq}$ & 8.95 & ${ }^{\mathrm{c}}$ \\
\hline OPD & 0 & 10 & 78.69 & $a-c$ & 51.17 & $\mathrm{ab}$ & 21.99 & $a-j$ & 4.82 & $\mathrm{q}$ & 16.86 & a-e \\
\hline OPD & 0 & 20 & 75.78 & $a-d$ & 50.53 & $\mathrm{ab}$ & 19.12 & $\mathrm{c}-1$ & 7.01 & k-p & 18.39 & a-d \\
\hline OPD & 75 & 0 & 80.16 & $a-c$ & 51.61 & $\mathrm{ab}$ & 18.33 & $f-1$ & 9.84 & ch & 20.81 & $a-d$ \\
\hline OPD & 75 & 10 & 82.04 & $\mathrm{ab}$ & 53.86 & $\mathrm{ab}$ & 22.48 & $\mathrm{~b}-\mathrm{i}$ & 8.91 & $\mathrm{~d}-\mathrm{I}$ & 11.98 & de \\
\hline OPD & 75 & 20 & 80.33 & $a-c$ & 44.38 & $\mathrm{ab}$ & 18.75 & $\mathrm{~d}-\mathrm{l}$ & 7.82 & h-o & 13.87 & b-e \\
\hline OPD & 150 & 0 & 80.16 & $a-c$ & 52.01 & $\mathrm{ab}$ & 25.82 & $a-c$ & 10.33 & b-f & 15.45 & b-c \\
\hline OPD & 150 & 10 & 78.10 & $a-c$ & 48.86 & $\mathrm{ab}$ & 23.79 & a-h & 9.32 & ${ }^{c-j}$ & 15.35 & b-c \\
\hline OPD & 150 & 20 & 83.40 & $\mathrm{a}$ & 53.58 & $\mathrm{ab}$ & 16.58 & ${ }^{i-1}$ & 7.42 & $\mathrm{j}-\mathrm{o}$ & 20.10 & a-d \\
\hline OPD & 225 & 0 & 80.28 & $a-c$ & 52.54 & $\mathrm{ab}$ & 21.91 & ${ }^{a-j}$ & 11.28 & $a-c$ & 14.13 & b-c \\
\hline OPD & 225 & 10 & 77.58 & $a-c$ & 47.92 & $\mathrm{ab}$ & 18.54 & $\mathrm{e}-1$ & 12.51 & $\mathrm{a}$ & 18.56 & a-c \\
\hline OPD & 225 & 20 & 76.49 & a-c & 57.25 & $\mathrm{a}$ & 27.22 & A & 12.30 & $\mathrm{ab}$ & 27.29 & $\mathrm{a}$ \\
\hline LPD & 0 & 0 & 75.14 & a-d & 46.43 & $\mathrm{ab}$ & 13.11 & $\mathrm{k}-\mathrm{l}$ & 6.89 & ${ }^{1-q}$ & 13.33 & c-e \\
\hline LPD & 0 & 10 & 73.16 & b-d & 48.92 & $\mathrm{ab}$ & 14.08 & $k-1$ & 8.74 & $e-m$ & 17.63 & $a-c$ \\
\hline LPD & 0 & 20 & 78.57 & a-c & 49.18 & $\mathrm{ab}$ & 21.99 & ${ }^{a-j}$ & 9.10 & $\mathrm{~d}-\mathrm{k}$ & 16.34 & b-e \\
\hline LPD & 75 & 0 & 71.35 & cd & 51.30 & $\mathrm{ab}$ & 23.63 & a-h & 9.68 & $\mathrm{c}^{\mathrm{c}-\mathrm{i}}$ & 12.16 & $\mathrm{de}$ \\
\hline LPD & 75 & 10 & 77.34 & $a-c$ & 51.83 & $\mathrm{ab}$ & 24.45 & ${ }^{a-g}$ & 10.08 & $c-c$ & 18.35 & a-e \\
\hline LPD & 75 & 20 & 78.45 & $a-c$ & 50.58 & $\mathrm{ab}$ & 24.66 & $\mathrm{a}-\mathrm{f}$ & 10.98 & $a-d$ & 15.83 & b-e \\
\hline LPD & 150 & 0 & 76.10 & $a-d$ & 48.63 & $\mathrm{ab}$ & 21.32 & ${ }^{a-j}$ & 8.41 & $\begin{array}{l}f-o \\
\end{array}$ & 13.69 & b-c \\
\hline LPD & 150 & 10 & 78.76 & $a-c$ & 50.37 & $\mathrm{ab}$ & 24.51 & a-g & 10.91 & a-o & 21.52 & a-d \\
\hline LPD & 150 & 20 & 77.13 & $a-c$ & 51.19 & $\mathrm{ab}$ & 25.46 & $a-c$ & 10.71 & $a-c$ & 14.15 & b-e \\
\hline LPD & 225 & 0 & 77.76 & $a-c$ & 49.65 & $\mathrm{ab}$ & 26.36 & $\mathrm{ab}$ & 8.71 & $\mathrm{e}-\mathrm{m}$ & 18.58 & a-c \\
\hline LPD & 225 & 10 & 78.88 & $a-c$ & 49.31 & $\mathrm{ab}$ & 25.56 & $a-d$ & 9.99 & $c-g$ & 17.62 & a-c \\
\hline LPD & 225 & 20 & 76.25 & a-d & 50.19 & $\mathrm{ab}$ & 22.14 & $a-j$ & 9.87 & d-h & 24.26 & $\mathrm{ab}$ \\
\hline VLPD & 0 & 0 & 61.64 & $\mathrm{c}$ & 21.63 & d & 12.73 & $\mathrm{~L}$ & 2.17 & r & 8.70 & $\mathrm{c}$ \\
\hline VLPD & 0 & 10 & 76.16 & a-d & 44.80 & $\mathrm{ab}$ & 13.60 & $\mathrm{kl}$ & 5.20 & $\mathrm{pq}$ & 16.20 & b-e \\
\hline VLPD & 0 & 20 & 76.50 & $a-c$ & 48.25 & $\mathrm{ab}$ & 15.54 & $\mathrm{j-1}$ & 6.58 & $\mathrm{n}-\mathrm{q}$ & 19.14 & a-c \\
\hline VLPD & 75 & 0 & 66.85 & $\mathrm{de}$ & 28.59 & cd & 17.45 & h-l & 5.22 & $\mathrm{pq}$ & 14.52 & b-c \\
\hline VLPD & 75 & 10 & 72.25 & cd & 43.08 & a-c & 17.89 & $f-1$ & 7.63 & i-o & 18.70 & a-c \\
\hline VLPD & 75 & 20 & 78.43 & $a-c$ & 46.08 & $\mathrm{ab}$ & 18.37 & $f-1$ & 7.51 & $j-0$ & 21.80 & a-d \\
\hline VLPD & 150 & 0 & 76.15 & $\mathrm{a}-\mathrm{d}$ & 39.01 & $\mathrm{bc}$ & 16.29 & ${ }^{i-1}$ & 6.34 & o-q & 15.47 & b-c \\
\hline VLPD & 150 & 10 & 76.55 & $a-c$ & 47.12 & $\mathrm{ab}$ & 18.23 & $f-1$ & 7.12 & k-p & 23.74 & a-c \\
\hline VLPD & 150 & 20 & 81.56 & $\mathrm{ab}$ & 48.83 & $\mathrm{ab}$ & 17.66 & $\mathrm{~g}-1$ & 8.48 & $\mathrm{f}-\mathrm{n}$ & 18.39 & a-e \\
\hline VLPD & 225 & 0 & 78.91 & $a-c$ & 46.80 & $\mathrm{ab}$ & 13.35 & $\mathrm{kl}$ & 6.76 & $\mathrm{~m}-\mathrm{q}$ & 18.36 & a-c \\
\hline VLPD & 225 & 10 & 76.76 & $a-c$ & 48.45 & $\mathrm{ab}$ & 18.38 & $f-1$ & 7.40 & $j-0$ & 20.27 & a-d \\
\hline VLPD & 225 & 20 & 77.56 & a-c & 49.05 & $\mathrm{ab}$ & 17.64 & $\mathrm{~g}-1$ & 7.90 & $\mathrm{~g}-\mathrm{o}$ & 18.03 & a-c \\
\hline
\end{tabular}

${ }^{*} \mathrm{OPD}, \mathrm{LPD}$, and VLPD indicate optimum, late, and very late planting dates, respectively. Means followed with at least one common letter in each column are not significantly different according to Duncan's multiple range tests $(\mathrm{P} \leq 0.01)$. 
Table 5. Grain yield, weight, and number per unit area of wheat over the two years of the experiment

\begin{tabular}{|c|c|c|c|c|c|c|c|}
\hline Year & RWC (\%) & $\begin{array}{c}\text { Chl a } \\
\left(\mathrm{mg} \mathrm{g}^{-1} \mathrm{FW}\right)\end{array}$ & $\begin{array}{c}\text { Carotenoids } \\
\left(\mathrm{mg} \mathrm{g}^{-1} \mathrm{FW}\right)\end{array}$ & $\begin{array}{c}\text { CMTS } \\
\left(\mu \mathrm{mhos}_{\mathrm{cm}}{ }^{-1}\right)\end{array}$ & $\begin{array}{c}\text { Grain yield } \\
\left(\mathrm{kg} \mathrm{ha}^{-1}\right)\end{array}$ & $\begin{array}{c}\text { 1000-Grain } \\
\text { weight }(\mathrm{g})\end{array}$ & $\begin{array}{c}\text { Grain number } \\
\text { per unit area }\left(\mathrm{m}^{2}\right)\end{array}$ \\
\hline 2018 & $72.49^{\mathrm{b}^{*}}$ & $20.52^{\mathrm{a}}$ & $23.60^{\mathrm{a}}$ & $71.04^{\mathrm{a}}$ & $4902^{\mathrm{a}}$ & $39.9^{\mathrm{a}}$ & $15927^{\mathrm{b}}$ \\
\hline 2019 & $81.41^{\mathrm{a}}$ & $19.97^{\mathrm{b}}$ & $10.76^{\mathrm{b}}$ & $24.30^{\mathrm{b}}$ & $4030^{\mathrm{b}}$ & $37.2^{\mathrm{b}}$ & $17808^{\mathrm{a}}$ \\
\hline
\end{tabular}

${ }^{*}$ Different letters indicate a significant difference $(\mathrm{P} \leq 0.01)$ according to Duncan's multiple range test.

Table 6. Means comparison for interaction between planting date and N-Zn fertilizers on grain yield and yield component of wheat

\begin{tabular}{|c|c|c|c|c|c|c|c|c|}
\hline \multirow{2}{*}{$\begin{array}{l}\begin{array}{c}\text { Planting } \\
\text { date }\end{array} \\
\text { OPD* }^{*}\end{array}$} & \multirow{2}{*}{$\begin{array}{c}\begin{array}{c}\text { Nitrogen } \\
\left(\mathrm{kg} \mathrm{ha}^{-1}\right)\end{array} \\
0\end{array}$} & \multirow{2}{*}{$\begin{array}{c}\begin{array}{c}\text { Zinc } \\
\left(\mathrm{kg} \mathrm{ha}^{-1}\right)\end{array} \\
0\end{array}$} & \multicolumn{2}{|c|}{$\begin{array}{l}\text { 1000-grain weight } \\
(\mathrm{g})\end{array}$} & \multicolumn{2}{|c|}{$\begin{array}{l}\text { Grain yield } \\
\left(\mathrm{kg} \mathrm{ha}^{-1}\right)\end{array}$} & \multicolumn{2}{|c|}{$\begin{array}{c}\text { Grain number per unit } \\
\text { area }\left(\mathrm{m}^{2}\right)\end{array}$} \\
\hline & & & 37.66 & e-I & 3634.3 & k-n & 1138 & op \\
\hline OPD & 0 & 10 & 40.63 & b-e & 4567.9 & $\mathrm{~d}-\mathrm{k}$ & 15032 & j-o \\
\hline OPD & 0 & 20 & 40.71 & b-e & 4233.3 & $\mathrm{f}-\mathrm{m}$ & 15762 & h-n \\
\hline OPD & 75 & 0 & 39.79 & $c-g$ & 4539.4 & $e-k$ & 17709 & $\mathrm{~d}-\mathrm{k}$ \\
\hline OPD & 75 & 10 & 43.07 & $\mathrm{~b}$ & 5995.9 & $a-c$ & 19585 & $\mathrm{~b}-\mathrm{i}$ \\
\hline OPD & 75 & 20 & 42.23 & $\mathrm{bc}$ & 5873.0 & $a-c$ & 21345 & $a-e$ \\
\hline OPD & 150 & 0 & 40.44 & b-f & 5005.1 & $c-j$ & 19851 & b-g \\
\hline OPD & 150 & 10 & 46.77 & $\mathrm{a}$ & 5988.4 & $a-c$ & 22628 & $\mathrm{ab}$ \\
\hline OPD & 150 & 20 & 47.13 & $\mathrm{a}$ & 6506.9 & $\mathrm{ab}$ & 21693 & $a-d$ \\
\hline OPD & 225 & 0 & 38.45 & $d-j$ & 5563.7 & b-e & 21775 & $a-c$ \\
\hline OPD & 225 & 10 & 40.61 & b-e & 5779.9 & $a-d$ & 21836 & $a-c$ \\
\hline OPD & 225 & 20 & 41.96 & $\mathrm{bc}$ & 6823.6 & $\mathrm{a}$ & 24122 & $\mathrm{a}$ \\
\hline LPD & 0 & 0 & 36.35 & i-n & 3097.3 & $\mathrm{mn}$ & 10519 & $P$ \\
\hline LPD & 0 & 10 & 38.59 & $e-j$ & 3246.3 & $1-n$ & 12563 & n-p \\
\hline LPD & 0 & 20 & 39.52 & c-h & 3453.3 & k-n & 13460 & 1-p \\
\hline LPD & 75 & 0 & 36.19 & $j-n$ & 3936.0 & $\mathrm{i}-\mathrm{m}$ & 16289 & $f-n$ \\
\hline LPD & 75 & 10 & 38.24 & $\mathrm{~d}-\mathrm{k}$ & 5095.6 & $\mathrm{c}-\mathrm{i}$ & 17359 & $e-1$ \\
\hline LPD & 75 & 20 & 38.68 & $d-j$ & 4545.0 & $e-k$ & 17818 & $c-k$ \\
\hline LPD & 150 & 0 & 37.41 & $f-1$ & 4552.7 & $e-k$ & 16799 & f-l \\
\hline LPD & 150 & 10 & 41.84 & $\mathrm{bc}$ & 5352.4 & b-g & 20084 & b-f \\
\hline LPD & 150 & 20 & 40.95 & b-d & 5436.7 & b-f & 19756 & b-h \\
\hline LPD & 225 & 0 & 35.74 & $j-n$ & 4931.7 & $c-j$ & 18325 & $c-j$ \\
\hline LPD & 225 & 10 & 36.99 & $\mathrm{~g}-\mathrm{I}$ & 5196.8 & $c-h$ & 18639 & $b-j$ \\
\hline LPD & 225 & 20 & 39.68 & d-h & 5499.4 & b-e & 19781 & b-h \\
\hline VLPD & 0 & 0 & 31.29 & $\mathrm{o}$ & 1839.0 & ${ }^{\circ}$ & 5917 & $\mathrm{q}$ \\
\hline VLPD & 0 & 10 & 36.49 & $\mathrm{~h}-\mathrm{m}$ & 2656.3 & no & 10270 & $\mathrm{P}$ \\
\hline VLPD & 0 & 20 & 37.30 & $\mathrm{~g}-\mathrm{I}$ & 3139.0 & $\mathrm{mn}$ & 12627 & m-p \\
\hline VLPD & 75 & 0 & 33.45 & no & 3850.3 & $j-n$ & 12519 & n-p \\
\hline VLPD & 75 & 10 & 36.24 & $j-n$ & 3037.1 & $\mathrm{mn}$ & 13904 & 1-p \\
\hline VLPD & 75 & 20 & 36.80 & $\mathrm{~g}-\mathrm{I}$ & 3567.3 & k-n & 16533 & $f-n$ \\
\hline VLPD & 150 & 0 & 35.35 & k-n & 3652.3 & k-n & 15682 & $\mathrm{i}-\mathrm{n}$ \\
\hline VLPD & 150 & 10 & 38.27 & $\mathrm{~d}-\mathrm{k}$ & 4086.0 & h-m & 16634 & $\mathrm{f}-\mathrm{m}$ \\
\hline VLPD & 150 & 20 & 37.15 & $\mathrm{~g}-\mathrm{l}$ & 4422.0 & $e-1$ & 17160 & $f-1$ \\
\hline VLPD & 225 & 0 & 33.50 & $\mathrm{~m}-\mathrm{o}$ & 3620.1 & k-n & 16030 & g-n \\
\hline VLPD & 225 & 10 & 35.11 & 1-n & 3894.5 & $\mathrm{i}-\mathrm{m}$ & 19515 & b-i \\
\hline VLPD & 225 & 20 & 37.52 & $f-1$ & 4154.2 & $g-m$ & 16230 & $\mathrm{~g}-\mathrm{n}$ \\
\hline
\end{tabular}

${ }^{*} \mathrm{OPD}, \mathrm{LPD}$, and VLPD indicate optimum, late, and very late planting dates, respectively. Means followed with at least one common letter in each column are not significantly different according to Duncan's multiple range tests $(\mathrm{P} \leq 0.01)$. 


\section{Hectolitre weight}

According to the compound analysis, the main effect of year and interaction of planting date $\times$ nitrogen $\times$ zinc on hectolitre weight was significant $(P \leq 0.01$, Table 10). The wheat grain's hectolitre weight was lower in the first year compared with the second year (Table 7).

Table 7. Some quality traits of wheat grain over the two years of experiment

\begin{tabular}{|c|c|c|c|}
\hline Year & $\begin{array}{c}\text { Grain hectolitre weight } \\
(\mathrm{g})\end{array}$ & $\begin{array}{c}\text { Grain protein } \\
(\%)\end{array}$ & $\begin{array}{c}\text { Grain zinc content } \\
\left(\mathrm{mg} \mathrm{kg}^{-1}\right)\end{array}$ \\
\hline 2018 & $79.79^{\mathrm{b}^{*}}$ & $10.22^{\mathrm{b}}$ & $1.53^{\mathrm{a}}$ \\
\hline 2019 & $81.52^{\mathrm{a}}$ & $12.22^{\mathrm{a}}$ & $1.42^{\mathrm{b}}$ \\
\hline
\end{tabular}

${ }^{*}$ Different letters indicate a significant difference $(\mathrm{P} \leq 0.01)$ according to Duncan's multiple range test.

Table 8. Means comparison for interaction between planting date and N-Zn fertilizers on some grain quality traits

\begin{tabular}{|c|c|c|c|c|c|c|c|c|}
\hline \multirow{2}{*}{$\begin{array}{l}\text { Planting date } \\
\text { OPD }\end{array}$} & \multirow{2}{*}{$\begin{array}{c}\begin{array}{c}\text { Nitrogen } \\
\left(\mathrm{kg} \mathrm{ha}^{-1}\right)\end{array} \\
0\end{array}$} & \multirow{2}{*}{$\begin{array}{c}\begin{array}{c}\text { Zinc } \\
\left(\mathrm{kg} \mathrm{ha}^{-1}\right)\end{array} \\
0\end{array}$} & \multicolumn{2}{|c|}{$\begin{array}{l}\text { Protein } \\
(\%)\end{array}$} & \multicolumn{2}{|c|}{$\begin{array}{c}\text { Zinc } \\
\left(\mathrm{mg} \mathrm{kg}^{-1}\right)\end{array}$} & \multicolumn{2}{|c|}{$\begin{array}{l}\text { Hectoliter weight } \\
\text { (g) }\end{array}$} \\
\hline & & & 7.58 & 1 & 1.11 & $\mathrm{t}$ & 79.14 & $\mathrm{j}-\mathrm{n}$ \\
\hline OPD & 0 & 10 & 8.23 & $\mathrm{j}-1$ & 1.42 & $j-p$ & 80.56 & $\mathrm{~d}-1$ \\
\hline OPD & 0 & 20 & 10.12 & $f_{-j}$ & 1.32 & n-q & 80.84 & $c-j$ \\
\hline OPD & 75 & 0 & 9.01 & ${ }^{i-1}$ & 1.29 & p-r & 81.63 & $\mathrm{a-g}$ \\
\hline OPD & 75 & 10 & 9.20 & $\mathrm{i}-1$ & 1.43 & i-o & 82.41 & $a-c$ \\
\hline OPD & 75 & 20 & 10.5 & $e^{e-i}$ & 1.52 & $\mathrm{~g}-1$ & 82.92 & $\mathrm{ab}$ \\
\hline OPD & 150 & 0 & 10.80 & $\mathrm{e}-\mathrm{i}$ & 1.39 & k-p & 82.39 & $a-c$ \\
\hline OPD & 150 & 10 & 11.32 & $\mathrm{ch}$ & 1.66 & $c-f$ & 82.69 & $\mathrm{ab}$ \\
\hline OPD & 150 & 20 & 11.27 & d-h & 1.68 & b-e & 83.25 & $\mathrm{a}$ \\
\hline OPD & 225 & 0 & 11.74 & ${ }^{a-g}$ & 1.52 & g-k & 82.24 & a-d \\
\hline OPD & 225 & 10 & 12.00 & $\mathrm{a}-\mathrm{f}$ & 1.80 & $\mathrm{ab}$ & 83.00 & $\mathrm{ab}$ \\
\hline OPD & 225 & 20 & 11.74 & $\mathrm{a-g}$ & 1.90 & $\mathrm{a}$ & 82.39 & $a-d$ \\
\hline LPD & 0 & 0 & 7.87 & $\mathrm{kl}$ & 1.16 & st & 79.69 & $\mathrm{~h}-\mathrm{m}$ \\
\hline LPD & 0 & 10 & 9.05 & $\mathrm{i}-1$ & 1.39 & $\mathrm{~m}-\mathrm{q}$ & 78.95 & $k-n$ \\
\hline LPD & 0 & 20 & 10.78 & $\mathrm{e}-\mathrm{i}$ & 1.38 & $\mathrm{~m}-\mathrm{q}$ & 80.80 & $c-j$ \\
\hline LPD & 75 & 0 & 10.40 & $\mathrm{e}-\mathrm{i}$ & 1.26 & $\mathrm{q}-\mathrm{s}^{-}$ & 79.86 & $\mathrm{~g}-\mathrm{m}$ \\
\hline LPD & 75 & 10 & 10.22 & $e^{e-i}$ & 1.53 & $f_{-j}$ & 81.28 & $\mathrm{~b}-\mathrm{i}$ \\
\hline LPD & 75 & 20 & 10.53 & ${ }^{\mathrm{e}-\mathrm{i}}$ & 1.44 & i-n & 81.80 & $\mathrm{a}-\mathrm{f}$ \\
\hline LPD & 150 & 0 & 12.17 & $a-c$ & 1.39 & ${ }^{1-q}$ & 80.34 & $\mathrm{c}^{-1}$ \\
\hline LPD & 150 & 10 & 11.80 & ${ }^{a-g}$ & 1.71 & b-d & 81.36 & b-h \\
\hline LPD & 150 & 20 & 11.97 & $a-f$ & 1.55 & $\mathrm{e}-\mathrm{i}$ & 81.95 & $\mathrm{a-c}$ \\
\hline LPD & 225 & 0 & 13.22 & $a^{a-d}$ & 1.41 & $j-p$ & 80.64 & $c-k$ \\
\hline LPD & 225 & 10 & 13.24 & $\mathrm{a-d}$ & 1.71 & b-d & 80.82 & $c-j$ \\
\hline LPD & 225 & 20 & 12.92 & ${ }^{a-d}$ & 1.78 & $\mathrm{bc}$ & 81.97 & $a-c$ \\
\hline VLPD & 0 & 0 & 10.40 & ${ }^{e-i}$ & 1.17 & $\mathrm{r}-\mathrm{t}$ & 77.40 & $\mathrm{n}$ \\
\hline VLPD & 0 & 10 & 9.18 & $\mathrm{~g}-\mathrm{k}$ & 1.29 & p-s & 79.63 & $\mathrm{~h}-\mathrm{m}$ \\
\hline VLPD & 0 & 20 & 9.62 & h-k & 1.30 & o-q & 79.85 & $\mathrm{~g}-\mathrm{m}$ \\
\hline VLPD & 75 & 0 & 11.48 & $\mathrm{~b}-\mathrm{h}$ & 1.26 & $\mathrm{q}-\mathrm{s}$ & 79.20 & $j^{j-n}$ \\
\hline VLPD & 75 & 10 & 11.37 & ch & 1.55 & $f_{-j}$ & 79.28 & $j-m$ \\
\hline VLPD & 75 & 20 & 12.13 & $a-c$ & 1.47 & $\mathrm{~h}-\mathrm{m}$ & 78.75 & $\mathrm{l}-\mathrm{n}$ \\
\hline VLPD & 150 & 0 & 13.47 & $\mathrm{ab}$ & 1.36 & $\mathrm{~m}-\mathrm{q}$ & 80.16 & e-m \\
\hline VLPD & 150 & 10 & 13.71 & $\mathrm{a}$ & 1.68 & b-e & 79.50 & i-m \\
\hline VLPD & 150 & 20 & 13.29 & $a-c$ & 1.59 & d-h & 79.61 & h-m \\
\hline VLPD & 225 & 0 & 13.67 & $\mathrm{a}$ & 1.47 & $\mathrm{~h}-\mathrm{m}$ & 78.93 & $k-n$ \\
\hline VLPD & 225 & 10 & 13.68 & $\mathrm{a}$ & 1.64 & $\mathrm{c-g}$ & 78.40 & $\mathrm{mn}$ \\
\hline VLPD & 225 & 20 & 13.68 & a & 1.61 & $\mathrm{c} \cdot \mathrm{g}$ & 79.98 & $\mathrm{f}-\mathrm{m}$ \\
\hline
\end{tabular}

${ }^{*} \mathrm{OPD}, \mathrm{LPD}$, and VLPD indicate optimum, late, and very late planting dates, respectively. Means followed with at least one common letter in each column are not significantly different according to Duncan's multiple range tests $(\mathrm{P} \leq 0.01)$. 
Delayed planting caused a reduction in hectolitre weight. The highest hectolitre weight $(83.00 \mathrm{~g})$ belonged to optimal planting date and the application of $225 \mathrm{~kg} \mathrm{~N} \mathrm{ha}^{-1}$ and $10 \mathrm{~kg} \mathrm{Zn} \mathrm{ha}^{-1}$. Very late planting date and no fertilizer treatment (control) yielded the lowest $(77.40 \mathrm{~g}$ ) hectolitre weight of grain, showing a $7 \%$ reduction (Table 7). At the late planting date, the fertilizer treatment of $150 \mathrm{~kg} \mathrm{ha}^{-1} \mathrm{~N}$ and $20 \mathrm{~kg} \mathrm{ha}^{-1}$ zinc, and at the very late planting date, the fertilizer treatment of $150 \mathrm{~kg} \mathrm{ha}^{-1} \mathrm{~N}$ without zinc enhanced the hectolitre weight of wheat grain (Table 8).

\section{Grain protein}

The compound analysis showed that the grain protein was meaningfully $(\mathrm{P} \leq 0.05)$ influenced by the year and interaction of planting date $\times$ nitrogen $\times$ zinc (Table 10). The grain protein was lower in the first year compared with the second year (Table 7). Delayed sowing increased the protein content; in other words, late and very late planting dates resulted in $14.67 \%$ and $17.98 \%$ more accumulation of protein in wheat grain than the optimal planting date. Mean comparison revealed that the highest protein content of grain $(13.71 \%)$ belonged to the very late planting date with the usage of $150 \mathrm{~kg} \mathrm{ha}^{-1} \mathrm{~N}$ and $10 \mathrm{~kg} \mathrm{ha}^{-1}$ zinc. Furthermore, the lowest values $(7.58 \%)$ were recorded under optimal planting date and no fertilizer use, showing a $44 \%$ reduction. However, at optimal planting date, $225 \mathrm{~kg} \mathrm{ha}^{-1} \mathrm{~N}$ and $10 \mathrm{~kg} \mathrm{ha}^{-1}$ zinc improved the grain protein (Table 8).

\section{Grain zinc content}

The main effect of year and interaction of planting date $\times$ nitrogen $\times$ zinc had a meaningful influence $(\mathrm{P} \leq 0.01)$ on the grain zinc content (Table 10). Heat stress, induced by delayed planting, did not affect the zinc content. In the first year, the amount of grain zinc was higher (Table 7). The highest zinc content $\left(1.9 \mathrm{mg} \mathrm{kg}^{-}\right.$ $\left.{ }^{1}\right)$ was achieved under optimal planting date and use of $225 \mathrm{~kg} \mathrm{ha}^{-1} \mathrm{~N}$ and $20 \mathrm{~kg} \mathrm{ha}^{-1}$ zinc. The lowest value $\left(1.17 \mathrm{mg} \mathrm{kg}^{-1}\right)$ was recorded when wheat was planted very late, and no fertilizers (nitrogen and zinc) were applied.

Wheat grains had higher protein content (20\%) and hectolitre weight $(3 \%)$ in the second year than the first year (Table 7). However, wheat's zinc content in the first year was more significant than in the second year (Table 7).

\section{Discussion}

\section{Physiological traits}

Damage to pigments such as chlorophyll is one of the effects of heat stress on plants. Reduction in chlorophyll content under heat stress is due to the increased activity of chlorophyllase (Kamanga et al., 2018). In the present research, delayed planting reduced the chlorophyll content by inducing heat stress. However, the application of nitrogen fertilizer resulted in increased chlorophyll content. Since nitrogen is one of the main elements of chlorophyll structure, its presence in plants increases chlorophyll synthesis. By affecting the chlorophyll concentration, nitrogen directly influences the photosynthesis rate (Evans, 1983) hence plant growth and yield.

Heat stress reduced chlorophyll biosynthesis and increased its degradation. The chlorophyll biosynthesis inhibition under high temperature is attributed to various enzymes' deactivation (Dutta et al., 2009), such as 5-aminolevulinate dehydratase, an essential enzyme in the pyrrole biosynthesis pathway, that its activity decreases in wheat under heat stress (Mohanty et al., 2006).

Cell membrane usually is the first part to be damaged by environmental stresses, so CMTS is a good indicator of heat stress damage to leaf cells. Delayed planting reduced CMTS (Table 4) as the wheat was exposed to more heat stress. This finding is consistent with the results of Damaris et al. (2016). The decrease in RWC was correlated with a reduction in CMTS (Table 10). Delayed planting and the fact that some growth 
stages of wheat coincided with heat stress resulted in reduced RWC; this may be attributed to the increasing effect of heat on evaporation and transpiration. When RWC was reduced and stomata closed, the wheat's cooling power decreased, leading to an increase in the temperature of the whole plant. With the rise in the canopy temperature, the internal temperature of cells was further increased, negatively affecting the whole cell, especially the membrane system. The changes in carotenoids content (Table 4) confirms these findings. Carotenoids play a role in the chloroplast as a pigment. However, their most important function is an antioxidant activity because they are responsible for preventing lipid peroxidation and alleviating environmental stress's adverse effects (Altuntas et al., 2018). Accordingly, the increased carotenoid content at delayed planting dates indicates that wheat experienced heat stress at late and very late planting dates, generating more carotenoids to reduce its heat stress effects on cell membranes.

Adverse effects of heat stress on RWC, chlorophyll content, and CMTS were reduced with nitrogen and zinc application (Table 4). Nitrogen can overshadow water losses by affecting stomatal behaviour and leaf area duration and postponing plant maturation (Holík et al., 2018). Zinc application has increased RWC in maize (Tohidi Moghadam et al., 2013). Increasing the amount of nitrogen and zinc resulted in the synthesis of more protein molecules in the cell membrane structure, reducing cellular leakage and increasing membrane stability under stress conditions (Gomez-Coronado et al., 2017). Zinc is involved in the activation of enzymes related to carbohydrate metabolism, maintenance of the integrity of cellular membranes, protein synthesis, regulation of auxin synthesis, and pollen formation (Marschner, 1995). Also, regulation and conservation of the gene expression required for environmental stress tolerance are dependent on zinc (Cakmak, 2000).

\section{Grain yield}

The results showed that grain yield was negatively affected by a delay in planting. The induced heat stress by delayed sowing reduced the plant's photosynthetic potential, leading to reduction of chlorophyll content, RWC (Table 4), and grain filling-period (Mondal et al., 2015; Moshatati and Mosavi, 2017). These processes ultimately reduced grain number per unit area and the mean grain weight as two main wheat grain yield components. In the second year, the grain number per unit area was more than that of the first year. However, grain yield was lower in the first year, which can be attributed to the lower grain weight in the first year. It seems that climatic parameters are useful in determining wheat grain yield. In the second year, precipitation and relative humidity were significantly higher than the first year (Table 2), resulting in yellow rust disease in the post-pollination stage (data not shown). This adverse condition and reduced sunny hours reduced assimilate allocation to grains, hence grain weight reduction (Table 6).

Grain weight depends on the rate and duration of the grain-filling period and is strongly affected by the environment. Therefore, any factor that reduces the duration or rate of the grain filling period will reduce grain weight (Joshi et al., 2016). Another reason for the loss of grain weight under heat conditions is the plant's inability to transport and convert photosynthetic materials to starch under heat stress conditions (Ahmed et al., 2017).

A decrease in the grain-filling period reduces mean grain weight under heat stress conditions. Although the grain filling rate increases under such an adverse condition, this increase cannot reimburse reducing grain weight due to the reduced grain filling period (Gupta et al., 2015). By inducing kernel abortion, heat stress leads to grain number and grain yield reduction (Zaki and Radwan, 2011). Similarly, in the present study, delayed planting caused heat stress on wheat and reduced the number of grains per unit area.

Nitrogen application alleviated the adverse effects of heat stress on grain number per unit area; specifically, at late and very late planting dates, with the usage of $225 \mathrm{~kg} \mathrm{ha}^{-1} \mathrm{~N}$, the number of grains per unit area enhanced by $55 \%$ and $21 \%$, respectively. Given the positive correlation between grain number per unit area and grain yield (Table 9), nitrogen increased grain yield by $60 \%$ and $53 \%$ under late and very late planting dates, respectively (Table 6). There is a reciprocal relationship between the number of grains per unit area and mean grain weight (Kutlu and Olgun, 2015); therefore, nitrogen application led to grain weight reduction in the present study. Another reason for the decrease in grain weight under increased nitrogen application is the 
prolonged vegetative growth period. This exposes the grain filling period to higher temperatures and exacerbated heat stress effects (Lotfi, 2013).

Table 9. Pearson correlation coefficients for measured traits

\begin{tabular}{|l|c|c|c|c|c|c|c|c|c|c|c|}
\hline & GY & GN & GW & RWC & CMTS & Chl a & Chl b & Car. & GP & GZC & HL \\
\hline GY & 1 & & & & & & & & & & \\
\hline GN & $0.63^{* *}$ & 1 & & & & & & & & & \\
\hline GW & $0.62^{* *}$ & $0.45^{* *}$ & 1 & & & & & & & & \\
\hline RWC & $0.10^{\text {ns }}$ & $0.36^{* *}$ & $0.09^{\text {ns }}$ & 1 & & & & & & & \\
\hline CMTS & $0.41^{* *}$ & $-0.02^{\text {ns }}$ & $0.41^{* *}$ & $0.41^{* *}$ & 1 & & & & & & \\
\hline Chl a & $0.27^{* *}$ & $0.20^{* *}$ & $0.07^{\text {ns }}$ & $0.000^{\text {ns }}$ & $0.15^{* *}$ & 1 & & & & & \\
\hline Chl b & $0.29^{* *}$ & $0.26^{*}$ & $0.08^{\text {ns }}$ & $0.10^{\text {ns }}$ & $0.17^{* *}$ & $0.85^{* *}$ & 1 & & & & \\
\hline Car. & $0.20^{* *}$ & $-0.10^{\text {ns }}$ & $0.14^{*}$ & $-0.26^{* *}$ & $0.66^{*}$ & $0.16^{* *}$ & $0.21^{* *}$ & 1 & & & \\
\hline GP & $-0.04^{\text {ns }}$ & $0.29^{* *}$ & $-0.25^{* *}$ & $0.24^{* *}$ & $-0.42^{* *}$ & $0.01^{\text {ns }}$ & $0.04^{\text {ns }}$ & $-0.12^{*}$ & 1 & & \\
\hline GZC & $0.49^{* *}$ & $0.42^{* *}$ & $0.31^{* *}$ & $0.01^{\text {ns }}$ & $0.30^{* *}$ & $0.35^{* *}$ & $0.41^{* *}$ & $0.44^{* *}$ & $0.246^{* *}$ & 1 & \\
\hline HL & $0.34^{* *}$ & $0.47^{* *}$ & $0.33^{* *}$ & $0.46^{* *}$ & $-0.24^{* *}$ & $0.18^{* *}$ & $0.19^{* *}$ & -0.16 & $0.15^{*}$ & $0.15^{*}$ & 1 \\
\hline
\end{tabular}

GY: grain yield; GN: Grain number per unit area; GW: 1000-grain weight; RWC: Relative water content; CMTS: Cell membrane thermal stability; Chl a: chlorophyll a; Chl b: Chlorophyll b: Car.: Carotenoids content; GP: grain protein; GZ: grain zinc content; HL: grain hectolitre. ns: not a significant difference; ${ }^{* *},{ }^{*}$ Significant at 0.01 and 0.05 of probability level, respectively.

Zinc has positive effects on the enzymatic systems of the plant, having catalytic or structural parts in protein synthesis and increased production capacity of photo-assimilates; therefore, zinc plays a significant role in spike formation and increasing yield of the grain through enhancing the yield components (Ahmadi et al., 2017; Singh, 2014). Application of zinc under heat stress conditions increases the grain yield (Kamaei et al., 2018). Zinc can also mitigate the effects of environmental stresses on plants by improving cellular stability (Torrion and Stougaard, 2017) and enhancing antioxidant activity (Yadavi et al., 2014). In the recent study, zinc alleviated the adverse effects of heat stress on grain yield components; in other words, at late and very late planting dates, the weight of the grain and grain number per unit area was improved by $7 \%, 11 \%$ and $26 \% 33 \%$, respectively. This ultimately led to a $26 \%$ (late planting date) and $33 \%$ (very late planting date) increase in grain yield. Because zinc had been applied when the plant had not yet experienced the heat stress; so maybe additionally stored zinc in the plant could play a beneficial role in increasing the grain weight (probably through increasing assimilates transfer to grain (Ma et al., 2017) and participate in the biosynthesis of growth regulators (Zand et al., 2009).

\section{Grain quality}

In the second year of the experiment, the grain's protein content was greater than that in the first year, which can be attributed to the smaller grain (Table 6) in the second year. About $70 \%$ of the grain weight of wheat comprises starch; thus, decreasing the accumulation of starch in the grain results in smaller and lighter grains (Hu et al., 2018). The enzymes involved in starch production are susceptible to high temperatures during the period of grain-filling. Reducing these enzymes' activity at temperatures above $22^{\circ} \mathrm{C}$ results in the reduction of starch accumulation (Farooq et al., 2011). There is an inverse relationship between the amount of starch and grain protein. Also, protein production has a lower sensitivity to higher temperatures than starch (Kutlu and Olgun, 2015); therefore, grains had lower starch and higher protein in the second year of the test (Table 7). Nitrogen fertilizers increase protein storage compared to carbohydrates in the grain (Joshi et al., 2016). ElHabbal et al. (2010) concluded that the increase in the grain's protein content using nitrogen fertilizer was related to the increase in essential amino acids, leading to higher nutritional values. 
Table 10. Compound analysis of variance (Mean squares) of the effects of nitrogen and zinc application under heat stress (induced via different planting dates) on some traits of wheat during two growing seasons (2017-18 and 2018-19)

\begin{tabular}{|c|c|c|c|c|c|c|c|c|}
\hline SOV & DF & RWC & CMTS & Chlorophyll a & Chlorophyll b & Carotenoid & $\begin{array}{c}\text { 1000-grain } \\
\text { weight }\end{array}$ & Grain yield \\
\hline YE & 1 & $5722.27^{* *}$ & $157328.71^{\prime \prime}$ & $13.59^{* *}$ & $88.00^{* *}$ & $1186.55^{* *}$ & $554.50^{* *}$ & $54768534.4^{* *}$ \\
\hline $\mathrm{B} \times \mathrm{YE}$ & 6 & 21.80 & 18.39 & 7.03 & 63.43 & 46.58 & 9.70 & 421876.7 \\
\hline PD & 2 & $474.38^{\mathrm{ns}}$ & $1833.90^{* *}$ & $312.16^{\mathrm{ns}}$ & $1356.83^{\text {ns }}$ & $134.84^{\mathrm{ns}}$ & $843.33^{\text {ns }}$ & $85360334.8^{\text {ns }}$ \\
\hline $\mathrm{PD} \times \mathrm{YE}$ & 2 & $33.27^{\text {ns }}$ & $8.89^{\mathrm{ns}}$ & $690.11^{* *}$ & $2154.20^{* *}$ & $1725.32^{* *}$ & $222.96^{* *}$ & $6817349.6^{* *}$ \\
\hline E1 & 12 & 23.27 & 41.52 & 8.90 & 17.32 & 65.56 & 4.10 & 727501.5 \\
\hline $\mathrm{N}$ & 3 & $190.90^{*}$ & $381.60^{\text {ns }}$ & $159.78^{*}$ & $307.47^{\text {ns }}$ & $273.47^{\mathrm{ns}}$ & $140.21^{\mathrm{ns}}$ & $46698751.9^{*}$ \\
\hline $\mathrm{N} \times \mathrm{YE}$ & 3 & $20.11^{\mathrm{ns}}$ & $59.13^{\text {ns }}$ & $17.36^{* *}$ & $53.90^{\circ}$ & $62.31^{\mathrm{ns}}$ & $60.10^{* *}$ & $2043038.8^{*}$ \\
\hline $\mathrm{PD} \times \mathrm{N}$ & 6 & $91.54^{\mathrm{ns}}$ & $135.52^{\text {ns }}$ & $6.52^{\text {ns }}$ & $36.27^{\mathrm{ns}}$ & $29.85^{\mathrm{ns}}$ & $17.57^{\mathrm{ns}}$ & $517398.3^{\text {ns }}$ \\
\hline $\mathrm{PD} \times \mathrm{N} \times \mathrm{YE}$ & 6 & $53.80^{*}$ & $154.51^{* *}$ & $6.89^{\text {ns }}$ & $14.35^{\mathrm{ns}}$ & $24.32^{\mathrm{ns}}$ & $18.26^{*}$ & $532010.4^{\mathrm{ns}}$ \\
\hline E2 & 54 & 19.80 & 24.50 & 3.19 & 14.17 & 26.78 & 6.16 & 526148.9 \\
\hline $\mathrm{Z}$ & 2 & $230.34^{*}$ & $860.08^{\text {ns }}$ & $26.17^{\mathrm{ns}}$ & $45.38^{\mathrm{ns}}$ & $532.73^{* *}$ & $370.44^{\mathrm{ns}}$ & $15680389.3^{\mathrm{ns}}$ \\
\hline $\mathrm{Z} \times \mathrm{YE}$ & 2 & $8.90^{\mathrm{ns}}$ & $252.93^{* *}$ & $44.70^{* *}$ & $186.51^{* *}$ & $3.05^{\mathrm{ns}}$ & $151.15^{* *}$ & $5894717.1^{* *}$ \\
\hline $\mathrm{Z} \times \mathrm{PD}$ & 4 & $152.27^{\mathrm{ns}}$ & $502.36^{\text {ns }}$ & $24.49^{\mathrm{ns}}$ & $23.07^{\mathrm{ns}}$ & $129.74^{\mathrm{ns}}$ & $3.12^{\mathrm{ns}}$ & $1509869.9^{\text {ns }}$ \\
\hline $\mathrm{Z} \times \mathrm{D} \times \mathrm{YE}$ & 4 & $100.79^{* *}$ & $142.36^{* *}$ & $5.60^{\mathrm{ns}}$ & 61.62 & $81.04^{*}$ & $2.62^{\text {ns }}$ & $671092.2^{\text {ns }}$ \\
\hline $\mathrm{Z} \times \mathrm{N}$ & 6 & $97.79^{\mathrm{ns}}$ & $221.41^{\text {ns }}$ & $11.52^{\mathrm{ns}}$ & $36.83^{\mathrm{ns}}$ & $100.28^{\text {ns }}$ & $12.32^{\mathrm{ns}}$ & $599584.4^{\mathrm{ns}}$ \\
\hline $\mathrm{Z} \times \mathrm{N} \times \mathrm{YE}$ & 6 & $94.36^{* *}$ & $96.10^{* *}$ & $14.05^{* *}$ & $63.43^{* *}$ & $104.95^{* *}$ & $9.52^{* *}$ & $2194838.7^{* *}$ \\
\hline $\mathrm{Z} \times \mathrm{N} \times \mathrm{PD}$ & 12 & $70.90^{*+}$ & $115.71^{* *}$ & $5.45^{* *}$ & $47.94^{* *}$ & $79.91^{* *}$ & $6.54^{*}$ & $11457780^{*}$ \\
\hline $\mathrm{Z} \times \mathrm{N} \times \mathrm{PD} \times \mathrm{YE}$ & 12 & $59.62^{* *}$ & $164.23^{* *}$ & $31.41^{*}$ & $2.93^{\mathrm{ns}}$ & $78.12^{* *}$ & $6.11^{*}$ & $984292.1^{*}$ \\
\hline E3 & 144 & 19.57 & 18.76 & 3.19 & 14.80 & 24.07 & 3.08 & 459217.7 \\
\hline $\mathrm{CV}(\%)$ & & 5.74 & 9.08 & 19.26 & 21.50 & 28.55 & 4.55 & 15.17 \\
\hline $\mathrm{SOV}$ & DF & \multicolumn{2}{|c|}{ Grain number per unit area } & \multicolumn{2}{|c|}{ Protein content } & \multicolumn{2}{|c|}{ Zinc content } & toliter weight \\
\hline YE & 1 & & $1267^{* *}$ & & & $0.99^{* *}$ & & $217.06^{* *}$ \\
\hline $\mathrm{B} \times \mathrm{YE}$ & 6 & & 2269 & & & 0.02 & & 2.59 \\
\hline PD & 2 & & $1727^{\mathrm{ns}}$ & & & $0.7^{\mathrm{ns}}$ & & $180.39^{\text {ns }}$ \\
\hline $\mathrm{PD} \times \mathrm{YE}$ & 2 & & $9011^{* *}$ & & & $0.48^{* *}$ & & $56.04^{* *}$ \\
\hline E1 & 12 & & 4431 & & & 0.02 & & 0.66 \\
\hline $\mathrm{N}$ & 3 & & $4711^{*}$ & & & $1.86^{*}$ & & $28.72^{\text {ns }}$ \\
\hline $\mathrm{N} \times \mathrm{YE}$ & 3 & & $3992^{*}$ & & & $0.08^{* *}$ & & $16.68^{* *}$ \\
\hline $\mathrm{PD} \times \mathrm{N}$ & 6 & & $021^{\mathrm{ns}}$ & & & $0.04^{\mathrm{ns}}$ & & $10.10^{\text {ns }}$ \\
\hline $\mathrm{PD} \times \mathrm{N} \times \mathrm{YE}$ & 6 & & $780^{\text {ns }}$ & & & $0.02^{\mathrm{ns}}$ & & $4.05^{\mathrm{ns}}$ \\
\hline E2 & 54 & & 0608 & & & 0.01 & & 3.36 \\
\hline $\mathrm{Z}$ & 2 & & $7704^{\mathrm{ns}}$ & & & $1.84^{\mathrm{ns}}$ & & $22.44^{\mathrm{ns}}$ \\
\hline $\mathrm{Z} \times \mathrm{YE}$ & 2 & & $4713^{* *}$ & & & $0.67^{* *}$ & & $2.99^{\text {ns }}$ \\
\hline $\mathrm{Z} \times \mathrm{PD}$ & 4 & & $030^{\mathrm{ns}}$ & & & $0.02^{\mathrm{ns}}$ & & $4.10^{\text {ns }}$ \\
\hline $\mathrm{Z} \times \mathrm{PD} \times \mathrm{YE}$ & 4 & & $540^{\mathrm{ns}}$ & & & $0.02^{\mathrm{ns}}$ & & $1.81^{\mathrm{ns}}$ \\
\hline $\mathrm{Z} \times \mathrm{N}$ & 6 & & $2889^{\text {ns }}$ & & & $0.02^{\mathrm{ns}}$ & & $1.77^{\text {ns }}$ \\
\hline $\mathrm{Z} \times \mathrm{N} \times \mathrm{YE}$ & 6 & & $3652^{* *}$ & & & $0.02^{*}$ & & $3.50^{\text {ns }}$ \\
\hline $\mathrm{Z} \times \mathrm{N} \times \mathrm{PD}$ & 12 & & $6830^{*}$ & & & $0.02^{\circ}$ & & $3.53^{\circ}$ \\
\hline $\mathrm{Z} \times \mathrm{N} \times \mathrm{PD} \times \mathrm{YE}$ & 12 & & $0140^{*}$ & & & $0.01^{\mathrm{ns}}$ & & $2.19^{\mathrm{ns}}$ \\
\hline E3 & 144 & & 4479 & & & 0.008 & & 1.76 \\
\hline $\mathrm{CV}(\%)$ & & & .85 & & & 6.35 & & 1.64 \\
\hline
\end{tabular}

$\mathrm{ns},{ }^{*},{ }^{* *}$ : non-significant and significant at $5 \%$ and $1 \%$ probability levels.

YE: year; B: Block; PD: Planting date; E1: Error1; N: Nitrogen; E2: Error 2; Z: Zinc; E3: Total Error.

Zinc can effectively determine the protein content of grain. In other words, it can increase the grain protein content associated with increased enzymatic activity (Aziz et al., 2019). Zandipour et al. (2018) showed the positive effect of zinc on the increased protein content of wheat grain. The present study's findings follow this because the correlation between protein and zinc content was positive and significant (Table 9). Giunta et al. (2019) concluded that zinc sulfate could increase the grain protein content, which agrees with the present research work results. However, the influence of zinc on the protein content of grain was affected by heat stress. At optimal and late planting dates, zinc application resulted in a $13 \%$ and $6 \%$ increase in the grain protein content, respectively; however, zinc had no positive influence on the wheat grain protein content at a very late 
planting date. In other words, the highest effect of zinc on the wheat grain protein content occurred under optimal planting dates and no heat stress imposed on the plant.

Hectolitre weight of grains is an indicator of grain yield and depends on uniformity in shape, density, and moisture content. Heat stress may reduce hectolitre weight, and grains damaged by stress also have a lower weight (Motaghi et al., 2012). Similar results were observed in the present study, where delayed planting (which induced heat stress on wheat) caused a reduction in hectolitre weight. This can be due to the negative effect of heat on starch accumulation and the increased bran to endosperm ratio (Ghodyeh Zarinabadi and Ehsanzadeh, 2014). On the other hand, nitrogen had no meaningful influence on hectolitre weight. In other words, nitrogen could not alleviate the negative influences of heat stress on hectolitre weight. These findings are in line with the results of Kazemzadeh et al. (2013), who stated that nitrogen had no effects on the hectolitre weight of wheat ('Alvand' cultivar). The present research work results showed a positive relationship between hectolitre weight and grain protein content (Table 9), which is consistent with Kazemzadeh et al. (2013).

\section{Conclusions}

Quantitative (grain $\mathrm{kg} / \mathrm{ha}$ ) and qualitative yields (protein and zinc content) of wheat were improved by integrating nitrogen and zinc fertilizers. The extent to which these fertilizers are used to maximize quantity and quality depends on the planting date. To achieve the highest grain yield, optimal planting date (November 22) and $225 \mathrm{~kg} \mathrm{ha}^{-1} \mathrm{~N}$ and $20 \mathrm{~kg} \mathrm{ha}^{-1}$ zinc is the best treatment. The highest protein content was obtained at a very late planting date with $150 \mathrm{~kg} \mathrm{ha}^{-1} \mathrm{~N}$ and $10 \mathrm{~kg} \mathrm{ha}^{-1}$ zinc. When zinc is considered a qualitative trait of wheat grain, the most optimal treatment is the first planting date (22 November), $225 \mathrm{~kg} \mathrm{ha}^{-1} \mathrm{~N}$ and $20 \mathrm{~kg} \mathrm{ha}^{-1} \mathrm{zinc}$. The treatment recommended for the maximum hectolitre weight is optimal planting date, $225 \mathrm{~kg} \mathrm{ha}^{-1} \mathrm{~N}$, and $10 \mathrm{~kg} \mathrm{ha}^{-1}$ zinc. The role of nitrogen in protein synthesis (HSPs to increase heat tolerance and gluten to increase seed quality) and development of area and photosynthesis efficiency is essential here. Zinc, by its various roles in cell metabolism, especially enzymatic reactions and carbohydrate metabolism, improved the quantity and quality of yield under normal and heat stress conditions.

According to the results of this two-year experiment, wheat's grain yield is affected by climatic conditions. Thus, the wheat grain yield was higher in the first year because, in the second year, the climatic parameters did not fully correspond to the plant's needs. In the second year of the experiment, climatic conditions such as higher rainfall, less sunshine, and higher relative humidity during the grain filling period resulted in reduced plant photosynthetic potential and increased pest damage (yellow rust, especially flag leafdata not shown), reducing the grain yield.

\section{Authors' Contributions}

Conceptualization: HRE and SNM; Investigation: NA and AM; Methodology: HRE, AM, and NA; Formal analysis: AI; Writing-original draft: SNM; and Writing-review and editing: HRE and SNM.

All authors read and approved the final manuscript. 


\section{Acknowledgements}

This research received no specific grant from any funding agency in the public, commercial, or not-forprofit sectors.

\section{Conflict of Interests}

The authors declare that there are no conflicts of interest related to this article.

\section{References}

Agarie S, Hanaoka N, Kubota F, Agata W, Kaufman PB (1995). Measurement of cell membrane stability evaluated by electrolyte leakage as drought and heat tolerance test in rice (Oryza sativa L.). Journal of the Faculty of Agriculture, Kyushu University 40:233-240.

Ahmadi M, Zare MJ, Emam Y (2017). Study some of morpho-physiological characteristics and grain yield of wheat affected by chlormequat chloride, zinc sulfate and nitroxin application. Journal of Plant Physiology 29:1-1.

Ahmed B, Ishag AA, Hassan MK (2017). Response of two wheat cultivars (Triticum aestivum L.) to amended nitrogen fertilizer on yield and grain quality in Halfa Elgadidah area. Biology and Medicine 1:133-136. https://doi.org/10.15406/mojbm.2017.01.00029

Altuntas O, Dasgan HY, Akhoundnejad Y (2018). Silicon-induced salinity tolerance improves photosynthesis, leaf water status, membrane stability, and growth in pepper (Capsicum annuum L.). Horticultural Science 53:1820-1826. https://doi.org/10.21273/HORTSCI13411-18

Arnon AN (1967). Method of extraction of chlorophyll in the plants. Agronomy Journal 23:112-121.

Asakereh-Nezhad S, Lak S (2017). Evaluation of the effect of planting date on the components of wheat cultivars production in hot and cold climate. Iranian Journal of Field Crop Science 4:551-564.

Aziz N, Anwar S, Kashmir S, Ahmad J, Saeed B, Khan S (2019). Response of wheat varieties to different zinc application methods. Pure and Applied Biology 8:489-495. http://dx.doi.org/10.19045/bspab.2018.700207

Bechoff A, Dhuique-Mayer C (2016). Factors influencing micronutrient bioavailability in biofortified crops. Annals of the New York Academy of Sciences 1-14. https://doi.org/10.1111/nyas.13301

Cakmak I (2000). Role of zinc in protecting plant cells from reactive oxygen species. New Phytologist 146:185-205. https://doi.org/10.1046/j.1469-8137.2000.00630

Chiranjib, DB Kumar KPS (2010). A potential medicinal importance of zinc in human health and chronic disease. Journal of Pharmaceutical and Biomedical Sciences 1:5-11.

Dai J, Bean B, Brown B, Bruening W, Edwards J, Flowers M, ... Wiersma J (2016). Harvest index and straw yield of five classes of wheat. Biomass and Bioenergy 85:223-228. https://doi.org/10.1016/j.biombioe.2015.12.023

Damaris RN, Li M, Liu Y, Chen X, Murage H, Yang P (2016). A proteomic analysis of salt stress response in seedlings of two African rice cultivars. Biochimica et Biophysica Acta - Proteins and Proteomics 1864:1570-1578. https://doi.org/10.1016/j.bbapap.2016.08.011

Dutta S, Mohanty, S, Tripathy, BC (2009). Role of temperature stress on chloroplast biogenesis and protein import in pea. Plant Physiology 150:050-1061. https://doi.org/10.1104/pp.109.137265

EL-Habbal MS, Ashmawy F, Saoudi HS, Abbas I (2010). Effect of nitrogen fertilizer rates on yield, yield components and grain quality measurements of some wheat cultivars using spad-meter. Egyptian Journal of Agricultural Research $88: 1-9$.

Evans, J R (1983). Nitrogen and photosynthesis in the flag leaf of wheat (Triticum aestivum L.). Plant Physiology 72:297302. https://doi.org/10.1104/pp.72.2.297

Fahad S, Bajwa AA, Nazir U, Anjum SA, Farooq A, Zohaib A, ... Huang J (2017). Crop production under drought and heat stress: plant responses and management options. Frontiers in Plant Science 8:1147. https://doi.org/10.3389/fpls.2017.01147

Farooq M, Bramley H, Palta JA, Siddique KHM (2011). Heat stress in wheat during reproductive and grain filling phases. Critical Reviews in Plant Sciences 30:491-507. https://doi.org/10.1080/07352689.2011.615687 
Ghodyeh Zarinabadi I, Ehsanzadeh P (2014). Evaluating quality attributes of three durum wheat genotypes under different plant densities in Isfahan. Journal of Cereal Research 2:115-125.

Giunta F, Pruneddu G, Motzo R (2019). Grain yield and grain protein of old and modern durum wheat cultivars grown under different cropping systems. Field Crops Research 230:107-120. https://doi.org/10.1016/j.fcr.2018.10.012

Gomez-Coronado F, Poblaciones MJ, Almeida AS, Cakmak I (2017). Combined zinc and nitrogen fertilization in different bread wheat genotypes grown under Mediterranean conditions. Cereal Research Communications 45:154-165. https://doi.org/10.1556/0806.44.2016.046

Gupta NK, Khan A, Maheshwari A, Narayan S, Chhapola OP, Arora A, Singh G (2015). Effect of post anthesis high temperature stress on growth, physiology and antioxidative defense mechanisms in contrasting wheat genotypes Indian Journal of Plant Physiology 20:103-110. https://doi.org/10.1007/s40502-015-0142-y

Hafez EM, Badawy SA (2018). Effect of bio fertilizers and inorganic fertilizers on growth, productivity and quality of bread wheat cultivars. Cercetari Agronomice in Moldova 4:1-16. https://doi.org/10.2478/cerce-2018-0031

Halim G, Emam, Y, Shakeri E (2018). Evaluation of yield, yield components and stress tolerance indices in bread wheat cultivars at post-anthesis irrigation cut-off. Journal of Crop Production and Processing 4:121-134. https://doi.org/10.29252/jcpp.7.4.121

Heckathorn SA, Poeller GJ, Coleman JS, Hallberg RL (1996). Nitrogen availability alters patterns of accumulation of heat stress-induced proteins in plants. Oecologia 105(3):413-418. https://doi.org/10.1007/BF00328745

Holík L, Hlisnikovský L, Kunzová E (2018). The effect of mineral fertilizers and farmyard manure on winter wheat grain yield and grain quality. Plant Soil and Environment 64:491-497. https://doi.org/10.17221/342/2018-PSE

Hu Y, Lu HF, Liu WX, Kang J, Ma G, Li SS, ... Wang CY (2018). Effects of high temperature and water deficiency during grain filling on activities of key starch synthesis enzymes and starch accumulation in wheat. Acta Agronomica Sinica 44:591-600.

Joshi MA, Faridullah S, Kumar A (2016). Effect of heat stress on crop phenology, yield and seed quality attributes of wheat (Triticum aestivum L.). Association of Agrometeorologists 18:206-215.

Kamaei H, Eisvand HR, Nazarian F (2018). Effects of planting date, bio-fertilizer containing P solubilizing bacteria and elements foliar application of zinc and boron on physiological and agronomic traits of bread wheat ('Aflak' cultivar). Iranian Journal of Field Crops Research 16:165-179. https://doi.org/10.22067/GSC.V16I1.61058

Kamanga RM, Mbega E, Ndakidemi P (2018). Drought tolerance mechanisms in plants: Physiological responses associated with water deficit stress in Solanum lycopersicum. Advances in Crop Science and Technology 6:362. https://doi.org/10.4172/2329-8863.1000362

Kazemzadeh M, Peighambardoust SH, Najafi N (2013). Effect of organic and nitrogen fertilizers on physicochemical properties and bread-making quality of wheat (Triticum aestivum cv. 'Alvand') Journal of Food Research 2:179197.

Kutlu I, Olgun M (2015). Determination of genetic parameters for yield components in bread wheat. International Journal of Biological Sciences 6(12):61-70. http://dx.doi.org/10.12692/ijb/6.12.61-70

Lotfi A (2013). The effect of end heat stress and optimal management of chemical, organic and biological fertilizer systems on agro ecological traits of wheat cultivars. Dissertation, Ramin University of Agriculture and Natural Resources.

Ma D, Sun D, Wang C, Ding H, Qin H, Hou J, ... Guo T (2017). Physiological responses and yield of wheat plants in zinc-mediated alleviation of drought stress. Frontiers in Plant Science 8:1-12. https://doi.org/10.3389/fpls.2017.00860

Marschner H (1995). Mineral nutrition of higher plants. (2nd Ed.). London: Academic Press.

Mohanty S, Baishna BG, Tripathy C (2006). Light and dark modulation of chlorophyll biosynthetic genes in response to temperature. Planta 224:692-699. https://doi.org/10.1007/s00425-006-0248-6

Mondal S, Singh RP, Kehel Z, Autrique E (2015). Characterization of heat- and drought-stress tolerance in high-yielding spring wheat. Crop Science 55:1-11. https://doi.org/10.2135/cropsci2014.10.0709

Moshatati A, Mosavi SE (2017). Bread wheat response to $\mathrm{Zn}$ in heat extreme heat conditions in Ahvaz. The 2nd International Congress and the Fourth National Congress on Iranian Agronomy and Plant Improvement. Iran.

Motaghi M, Sakinejad T, Mohammadi SA (2012). Technology of wheat quality. Behta Pajoohesh Press.

Niazkhani SM, Mandoulakani BA, Jafari M, Sadaghiani MR (2018). Studying the expression of ZIP1, ZIP3 and ZIP6 genes in bread wheat under $\mathrm{Zn}$ deficiency conditions. Cereal Research Communications 3:345-358. https://doi.org/10.22124/C.2018.10940.1413 
Niyigaba A, Twizerimana A, Mugenzi I, Ngnadong WA, Ye YP, Wu BM, Hai JB (2019). Winter wheat grain quality, zinc and iron concentration affected by a combined foliar spray of zinc and iron fertilizers. Agronomy 9:1-18. https://doi.org/10.3390/agronomy9050250

Pireivatlou AS, Dehdar Masjedlou B, Ramiz TA (2010). Evaluation of yield potential and stress adaptive trait in wheat genotypes under post anthesis drought stress conditions. African Journal of Agricultural Research 5:2829-2836.

Rehman SU, Bilal M, Rana RM, Tahir MN, Shah MKN, Ayalew H, Yan G (2016). Cell membrane stability and chlorophyll content variation in wheat (Triticum aestivum) genotypes under conditions of heat and drought. Crop and Pasture Science 67:712-718. https://doi.org/10.1071/CP15385

Saleem I, Javid S, Ehsan S, Niaz A, Bibi F, Ahmed ZA (2015). Improvement of wheat grain zinc and zinc daily intake by biofortification with zinc. International Journal of Plant \& Soil Science 8(5):1-6. https://doi.org/10.1016/j.jcs.2013.09.001

Singh KK (2014). Response of Zinc fertilization to wheat on yield, quality, nutrients uptake and soil- fertility grown in a zinc deficient soil. European Journal of Academic Essays 1:22-26.

Tohidi Moghadam HR, Zahedi H, Ashkiani A (2013). Effect of zinc foliar application on auxin and gibberellin hormones and catalase and superoxide dismutase enzyme activity of corn (Zea mays $L)$ under water stress. Article in Maydica 58:218-223.

Torrion JA, Stougaard RN (2017). Impacts and limits of irrigation water management on wheat yield and quality. Crop Science 57:3239-3251. https://doi.org/10.2135/cropsci2016.12.1032

Velu G, Guzman C, Mnodal C, Autrique JE, Huerta J, Singh RP (2016). Effect of drought and elevated temperature on grain zinc and iron concentration in CIMMYT spring wheat. Journal of Cereal Science 69:82-186. https://doi.org/10.1016/j.jcs.2016.03.006

Yadavi AR, Saeidi Aboueshaghi R, Movahhedi Dehnavi M, Balouchi H (2014). Effect of micronutrients foliar application on grain qualitative characteristics and some physiological traits of bean (Phaseolus vulgaris L.) under drought stress Indian Journal of Fundamental and Applied Life Sciences 4:124-131.

Yang N, Wang Z, Gao Y, Zhao H Li K Li F, Malhi SS (2014). Effects of planting soybean in summer fallow on wheat grain yield, total $\mathrm{N}$ and $\mathrm{Zn}$ in grain and available $\mathrm{N}$ and $\mathrm{Zn}$ in soil on the Loess Plateau of China. European Journal of Agronomy 58:63-72. https://doi.org/10.1016/j.eja.2014.05.002

Zaki RN, Radwan TE (2011). Improving wheat grain yield and its quality under salinity conditions at a newly reclaimed soil by using different organic sources as soil or foliar applications. Journal of Applied Sciences Research 7:42-58.

Zand B, Sorooshzadeh A, Ghanati, Moradi F (2009). Effect of zinc and auxin foliar application on grain yield and its components of grain maize under water deficit conditions. Seed and Plant Improvement Journal 25:448-431.

Zandipour E, Ajam norozei H, Bostani A (2018). Effect of zinc and iron foliar application in irrigation water acidity on wheat. Applied Ecology and Environmental Research 16:3097-3112. http://dx.doi.org/10.15666/aeer/1603_30973112

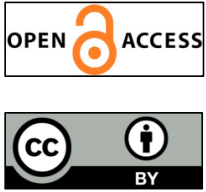

The journal offers free, immediate, and unrestricted access to peer-reviewed research and scholarly work. Users are allowed to read, download, copy, distribute, print, search, or link to the full texts of the articles, or use them for any other lawful purpose, without asking prior permission from the publisher or the author.

License - Articles published in Notulae Botanicae Horti Agrobotanici Cluj-Napoca are Open-Access, distributed under the terms and conditions of the Creative Commons Attribution (CC BY 4.0) License. (c) Articles by the authors; UASVM, Cluj-Napoca, Romania. The journal allows the author(s) to hold the copyright/to retain publishing rights without restriction. 